\title{
Social Communication Apprehension, Self-Esteem and Facebook Addiction Among University Students in Uganda
}

\author{
Ayodeji Awobamise \\ Kampala International University, Uganda \\ ORCID: 0000-0003-1474-3553 \\ Yosra Jarrar \\ American University in Dubai, United Arab Emirates \\ ORCID: 0000-0003-1595-0933 \\ Gabriel E. Nweke \\ Girne American University, Cyprus \\ ORCID: 0000-0003-2067-4494
}

Received: 10 Dec 2021

Accepted: 8 Jan 2022

\begin{abstract}
This study aimed at furthering the research on the relationship between social communication apprehension, self-esteem and Facebook addiction. To measure the three variables, a questionnaire comprised of The Personal Report of Communication Apprehension (PRCA-24), The Rosenberg SelfEsteem Scale (RES), and The Bergen Facebook Addiction Scale (BFAS) was administered to 654 university students in Uganda. Pearson's correlation analysis and multiple linear regression coefficient analysis were carried out. A positive significant relationship between communication apprehension and Facebook addiction and a negative significant relationship between self-esteem and Facebook addiction were reported. Findings further revealed that self-esteem and communication apprehension significantly predicted Facebook addiction.
\end{abstract}

Keywords: social communication apprehension, self-esteem, Facebook addiction, Uganda

\section{INTRODUCTION}

Social network sites can be defined as "web-based services that allow individuals to (1) construct a public or semi-public profile within a bounded system, (2) articulate a list of other users with whom they share a connection, and (3) view and traverse their list of connections and those made by others within the system" (Boyd \& Ellison, 2007, p. 211). Social Network Sites (SNSs) allow users the opportunity to carry out different activities such as sending messages, sharing pictures, videos, and texts, connecting with friends, following their favorite public figures amongst many other things (Kaplan \& Haenlein, 2010). Rohani and Hock (2010, p. 42) probably described it best, when they stated that

\footnotetext{
"Social networking services offer friends a space where they can maintain their relationships, chat with each other and share information. Moreover, they offer the opportunity to build new relationships through existing friends."
}

Facebook is arguably the most popular and widely used social networking site, boasting of over 2.85 billion monthly active users in the world (Statista, 2021) and yet, engagement continues to grow. Uganda has about 
2 million monthly active users, representing about 5 percent of its population. While social media usage in Uganda is not very high, it is worth noting that Uganda has a young population of which $60 \%$ has access to a cellphone. The growth rate in social media usage between 2019 and 2020 was $27 \%$, meaning that in less than 4 years, the number of social media users in the country should double (ISS, 2021). This upward trend should not be a big surprise considering the ubiquity of the internet and easy access to these platforms which makes communication and social interactions a lot easier.

Social interactions are one of the key functions of social media. One thing that differentiates social media from traditional media like TV and Radio is the ability to facilitate such social interactions (Wang et al., 2012). The word social in social media clearly informs to its purpose. Social media allows people from different parts of the world to connect and keep in touch, share their lives' journey with friends, families and online networks from the comfort of an internet enabled device. While the anonymity provided by the internet makes it easier for people to share information and even reveal personal experiences, they would otherwise have kept a secret (Awobamise et al., 2019), people still suffer from social anxiety or communication apprehension when venturing into the social media space or as a result of using social media (McCroskey, 2009). Social media apprehension is a widely studied phenomenon since the 1960s. With the advent of new communication technologies, the interest in communication apprehension is further rekindled. Self-esteem is another area of human behavior that is widely studied as it relates to social media usage, some studies have shown that social media usage can lead to lower self-esteem (Muqaddas et al., 2017).

From the foregoing, it appears that that there is little consensus on the relationship between social communication apprehension, self-esteem and Facebook addiction. However, very few studies have addressed how these three variables interact as the majority of the studies reviewed focus on understanding the relationship between communication apprehension and social media usage or self-esteem and social media usage. It was therefore based on this premise, that the researchers sought to understand how social communication apprehension, and self-esteem influence social media usage, with specific focus on Facebook addiction.

\section{THEORETICAL PERSPECTIVE}

This study shall be premised on two competing theories, namely; 'the rich gets richer' and 'the poor gets richer'. The rich gets richer effect is also referred to as the social enhancement or the Matthew effect and suggests that people who are socially adept offline are also going to be great at online social environments. The poor gets richer hypothesis, also referred to as the social compensation effect, suggests that those who are socially awkward or inept offline are going to spend a lot of time online, trying to compensate for their offline failings (Tufekci, 2010; Zywica \& Danowski, 2008).

Zywica and Danowski (2008) tested these hypotheses in their study on predicting Facebook and offline popularity of individuals based on their online behavior. The study involved 614 participants from a big urban university in the US. The findings showed that extroverted individuals with high levels of self-esteem are usually popular both offline and online while those that are not popular offline tend to support the social compensation hypothesis because they are also more likely to be introverted, have a low self-esteem and aim to compensate for their 'character flaw' by trying to look more popular on social media.

A different study by Tufekci (2010) found out that certain character and personality traits enable some people create online relationships and others to focus more on creating offline relationships. Findings have shown that when people are not good at interpersonal communication, they often turn to the mass media or social media to find an alternate solution to their loneliness and make up for their lack of interpersonal communication skills (Wang et al., 2008). A study by Erdogan (2008) found out that adolescents who spend a significant amount of time on social media tend to also be very lonely in real life. In support of the social enhancement effect, findings by Miyata and Kobayashi (2008) found out that individuals that are popular offline and good at face-to-face interactions are also very adept in the use of social media as a way of keeping in touch with their already extensive social networks. This is supported by Sheldon (2008) who similarly found 
out that people who were willing and able to communicate offline are also more likely to be very active in online relationships.

These theories are relevant to this study because they set the stage for understanding why certain people are more likely to develop social relationships online and others simply cannot do the same. Also, by confirming or refuting these theories, the study will invariably contribute to the development and understanding of the predictors of online socializing behavior and Facebook addiction.

\section{LITERATURE REVIEW}

Communication apprehension is one of the most commonly discussed and researched concepts in the field of communication (Wrench et al., 2008) and it has been the case since before the inception of mediated communication. The invention of radio and other mediated forms of communication further solidified its place as a bonafide area of research as scholars sought to understand how mediated communication affects the communication in general and how people make use of media.

Communication can be described as the process by which one person stimulates meaning in the mind of someone else (Agrawal \& Krishna, 2021; Richmond \& McCroskey, 1995). Richmond and McCroskey (1995) in their definition of communication identified three types of communication, namely; accidental, rhetorical and expressive. Accidental can be described as when communication takes place unintentionally. For instance, the gestures we make, the way we walk and the way we look can all stimulate meaning in a second party that we had no intention of speaking or communicating with. Expressive communication can be described as showing emotions by an individual and can also be unintentional or intentional. For instance, the look a mum gives an erring child can be categorized as expressive communication. Finally, Rhetorical communication refers to a situation when the source or originator of the message is intentionally trying to stimulate a particular meaning in the mind of the receiver using both verbal and non-verbal cues. Understanding communication and the different communication scenarios is important in understanding communication apprehension.

McCroskey in 1985 coined the term "communication apprehension" and described it as the fear or anxiety associated with either real or anticipated communication with another person or persons" (Richmond \& McCroskey, 1995, p. 35). Communication apprehension is linked to different types of social withdrawal behaviors such as, the need to live in a remote area, the fear of talking, the need to sit away from a group or be separated from a crowd (McCroskey \& Sheahan, 1978; Sealy, 2021). People with such behavioral traits often avoid communicative contact (Berger et al., 1984; Loureiro et al., 2020). Studies by Watson (2007) showed that people with high levels of communication apprehension are significantly less likely to communicate with people than those with low communication apprehension levels. Those with extreme apprehension avoid communicative contact mainly due to anxiety or fear which they have associated with communication over the years. These fears and anxieties might stem from ridicule, bullying and other negative behaviors that have been exhibited against them and which they have now associated with communicating. So, to avoid these awkward social situations, they choose to largely keep quiet. While some suffer from extreme cases of communication apprehension, other suffer from a mild case of communication apprehension and might not exhibit any fear or anxiety during interactions (Pitt \& Ramaseshan, 1990).

According to Armstrong and Rubin (1989) people who have some level of communication apprehension generally prefer to make use of a medium instead of communicating face-to-face. Findings by these scholars show that people who preferred talking on radio programs do not like interacting face-to-face and those same people who talk on radio programs also spend a lot of time listening to the radio. A different study by Scott and Rockwell (1997) found out that people who have communication apprehension preferred to communicate through the use of pagers, cell phones and other media that do not require in-person interactions. In a more recent study, Burke et al. (2010) found out that people that feel lonely and alone tend to make use of social networking sites more frequently. Similarly, another study by McCord et al. (2014) found that people with high levels of social anxiety tend to make use of social media more frequently than those with lower levels of social anxiety. 
Similarly, a study by Punyanunt-Carter et al. (2018) that sought to understand the connection between college students' use of social media and communication apprehension, showed that for college students social media communication apprehension was significantly related to pathological social media usage. They explained that people that have a difficulty communicating in real life might gravitate towards social media more. In a similar vein and more recently, a study by Gadekar and Ang (2020) showed that introverts, who generally suffer from communication apprehension, are more likely to engage their social media followers more and are generally more likely to make use of social media for socializing and communication.

From the foregoing, it is clear that social communication anxiety can lead to more social media usage due to the anonymity the social media environment provides and allows. In view of this, the researchers propose the following hypothesis:

H1: There is a difference in the frequency of social media usage among those who have high levels of communication apprehension and those with low levels or no communication apprehension.

Studies on self-esteem and the use of social media have also been a common area of research in recent times. Boyd and Ellison (2007) surmised in their studies on social media usage that the use of personal profiles on Facebook and other social media sites that allow users to view, scrutinize, pass judgement, and give feedback makes people feel more connected and can also help them build new relationships. The opinions of people on social media can have a very significant effect on the self-esteem of individuals on the receiving end of such comments. Heatherton and Polivy (1991) suggested in their work that self-esteem can be stable or mercurial in nature. What this means is that a high self-esteem can take time to develop in others and for some their level of self-esteem can fluctuate depending on daily events occurring in their lives. Therefore, negative feedback on social media has the tendency of reducing the self-esteem of social media users while positive feedback can have the opposite effect (Valkenburg, 2017).

Nyagah et al. (2015), as cited in Muqaddas et al. (2017), found out that social media gives its users a sense of identity and unmatched freedom to be whoever they want to be. They go on to explain that this freedom and identity made possible by social media also help boost confidence levels of their users. An earlier study also alluded to this fact stating that social media provides an avenue for shy and introverted individuals to develop some social capital because it reduces the restrictions involved in face-to-face communication (Ellison et al., 2007).

Affiliation or feeling of belongingness is one of the major motivators for social interactions according to Schachter (1959). To achieve this feeling of belonging to a social group, class or status, people often find themselves comparing themselves with others. These feelings of affiliation and belongingness are usually triggered on social networking sites (Muqaddas et al., 2017). Muqaddas et al. (2017) go on to explain that social networking sites make a lot of people self-evaluate and make social comparisons with others on the networks based on beauty, popularity, wealth, social class and many more, which may have a negative effect on their self-esteem. Feinstein et al. (2013) surmised in their study that there is a significant relationship between frequent use of Facebook and increase in depression and reduction in prosperity. They interpreted this as meaning that those who spend a lot of time on Facebook are significantly more likely to have higher levels of depression and lower levels of prosperity than their colleagues who spend less time on Facebook. This finding was supported by those of Kross et al. (2013) who found out that although people come on Facebook to escape loneliness, they almost always end up feeling less satisfied with their lives. This can perhaps be attributed to the fact that a lot of people who make use of social media have the erroneous belief that others are living significantly healthier and better lives than themselves (Chou \& Edge, 2012). These assumptions about the quality of life of other members of a social network may in certain cases result in depression, psychotic behavior and low self-esteem (Pantic, 2014). Similarly, studies by Hawi and Samaha (2016), Kose and Dogan (2019), and Purnama et al. (2021) showed a negative correlation between social media usage and self-esteem.

However, not all studies found a negative effect of social media usage on self-esteem. Valkenburg et al. (2006) explained that the internet is more to blame for lower self-esteem and not necessarily social media. However, this submission is a bit dated now, considering the fact that as at the time of their study, social 
media sites such as Facebook, Twitter, and even YouTube were not fully developed the time and those that existed, did not have the influence that social media has today. A more recent study by Tazghini and Siedlecki (2013) argued that Facebook is beneficial to people with low self-esteem as it allows them more social capital than those with high self-esteem. The implication is that those with low self-esteem now have an opportunity to develop a social life conveniently and can even help in improving their self-esteem in the long run, while those with already high self-esteem might not see a significant change in their social capital since they already have a great social life outside of social media.

From the foregoing, it is clear that the majority of studies have focused on the effect of social media usage on self-esteem, while there is an obvious dearth of literature on the effect of self-esteem on social media usage. Based on this premise, the researchers propose the following hypotheses:

H2: There is a significant relationship between self-esteem and Facebook addiction.

H3: Those with low self-esteem are significantly more likely to be addicted to social media than those with high self-esteem.

Finally, based on the literature reviewed, a few studies have been carried out that considered a combination of social communication apprehension and low self-esteem as a predictor of Facebook addiction. It is therefore based on this, that the following hypothesis was developed:

H4: Social communication apprehension and self-esteem is a predictor to Facebook addiction.

\section{METHODOLOGY}

\section{Research Approach}

This study made use of quantitative research approach that involved the distribution of questionnaires to a sample of the study population. Quantitative research, according to Creswell (2003) can be used to find out the relationships between variables within a particular study. Since this study seeks to explain the relationship between social communication apprehension, self-esteem and Facebook addiction with data that was collected quantitatively, then this approach is the most appropriate.

\section{Participants}

This study involved students from two universities in Uganda- Kampala International University (KIU) and Kyambogo University (KYU). According to 4icu's website, KIU is the best private university in the East Africa and ranks among the top 50 universities on the African continent. Similarly, Kyambogo university is the $3^{\text {rd }}$ best university in Uganda and the $2^{\text {nd }}$ best public university in the country. KIU attracts a lot of international students and lecturers while KYU attracts mostly local staff and students. These institutions were chosen because they are situated in Kampala (the capital city of Uganda) where there is an easy access to quality internet. Also, according to Facebook analytics page, over $90 \%$ of Facebook users are situated in Kampala, therefore, it was only ideal that institutions based in Kampala were selected for this study. Secondly, KIU is a multicultural and highly diverse institution and Kyambogo is highly localized (catering mostly to Ugandans), therefore, it is assumed that between these two schools, this study should be able to get the feedback from a rich and heterogeneous audience which should strengthen the results of the study. In total, 654 students participated in this study, $53 \%$ were male and $47 \%$ were female. Their ages ranged from $18-34$ years of age, with a mean age of 22.5 years. The average age was 23 and 22.3 years of the males and females, respectively.

\section{Measures}

This study aimed to measure three variables, namely; social communication apprehension, self-esteem, and Facebook addiction. To do this, the researchers opted to make use of a questionnaire that combines The Personal Report of Communication Apprehension (PRCA-24), The Rosenberg Self-Esteem Scale (RES), and The Bergen Facebook Addiction Scale (BFAS). To reduce the chances of common method bias from coming up in this study, the researchers opted to ensure that the questions developed for the three variables in this 
Table 1. Sample size distribution

\begin{tabular}{|c|c|c|}
\hline Institution & Faculty & Sample size \\
\hline \multirow{6}{*}{ Kyambogo University } & Faculty of Arts and Social Sciences & 70 \\
\hline & Faculty of Education & 55 \\
\hline & Faculty of Engineering & 45 \\
\hline & Faculty of Science & 48 \\
\hline & Faculty of Special Needs and Rehabilitation & 92 \\
\hline & Faculty of Vocational Studies & 51 \\
\hline \multirow{6}{*}{ Kampala International University } & College of Humanities and Social Sciences & 85 \\
\hline & College of Economics and Management & 70 \\
\hline & College of Education, Open and Distant Learning & 75 \\
\hline & School of Mathematics and computing & 45 \\
\hline & School of Engineering and Applied Sciences & 38 \\
\hline & School of Law & 65 \\
\hline Total & & 654 \\
\hline
\end{tabular}

study were obtained from different sources. The items of the questionnaire were carefully crafted to ensure that the questions were contextualized to the study population and therefore easy to understand, also vagueness and ambiguities were completely removed from the questionnaire. This ensured that the respondents could properly understand and answer the questions asked. Finally, an exploratory factor analysis was carried out on the questionnaire to ensure that no substantial amount of variance is present in the questionnaire. By carrying out this test, all questions that were not necessarily needed to achieve the study objectives and test the hypotheses were removed.

The Personal Report of Communication Apprehension (PRCA-24) is an instrument that is widely used and accepted to measure communication apprehension. The instrument is made up of 24 questions and is reliable (alpha>.90) and has a high level of predictability (predictive validity). The PRSA makes it possible to collect sub-scores for public speaking, dyadic interaction, large groups and small groups. In this study, the researchers took sub-scores for all different categories when seeking to measure communication apprehension among the participants of this study.

To measure self-esteem, the researchers made use of The Rosenberg Self-Esteem Scale (RES). This scale is widely used to measure self-esteem for the purpose of research. The instrument consists of 10 questions to which respondents are expected to answer using a 4-point Likert scale with 1 being strongly agree and 4 being strongly disagree. While scores less than $15 / 30$ reflect a low level of self-esteem, scores above $15 / 30$ reflect a high level of self-esteem.

Finally, to measure Facebook addiction, the researchers made use of The Bergen Facebook Addiction Scale (BFAS) developed by Andreassen et al. (2012) and used by da Veiga et al. (2019). The scale has six items that measure the level of Facebook addiction via self-reporting. Each item on the scale corresponds to one of six components of addiction as proposed by Griffiths (2005). These components include, mood modification, withdrawal symptoms, conflict, tolerance, salience, and relapse. Respondents are expected to state how frequently they have experienced any of these symptoms in the last 12 months and score their response on a scale of 1 to 5 with 1 being very rarely to 5 being very frequently. The overall score ranges from 6 to 30 and the higher the score, the more addicted the respondent is to Facebook and vice versa (Andreassen et al., 2012). It has also been suggested that a score of 3 or more for at least 4 of the 6 items in the instrument is a strong indication of Facebook addiction. In total, the questionnaire used in this study had 40 Likert scale questions (or statements).

\section{Procedure}

To ensure that the questionnaires were equitably distributed, the researchers made use of stratified random sampling. The sample population was sub-divided into different strata to include different faculties in each institution and then students from each faculty were randomly selected to fill the questionnaire. This way every faculty is properly represented in the study and thus the results are expected to be more valid. The breakdown of the distribution is shown in Table 1. 


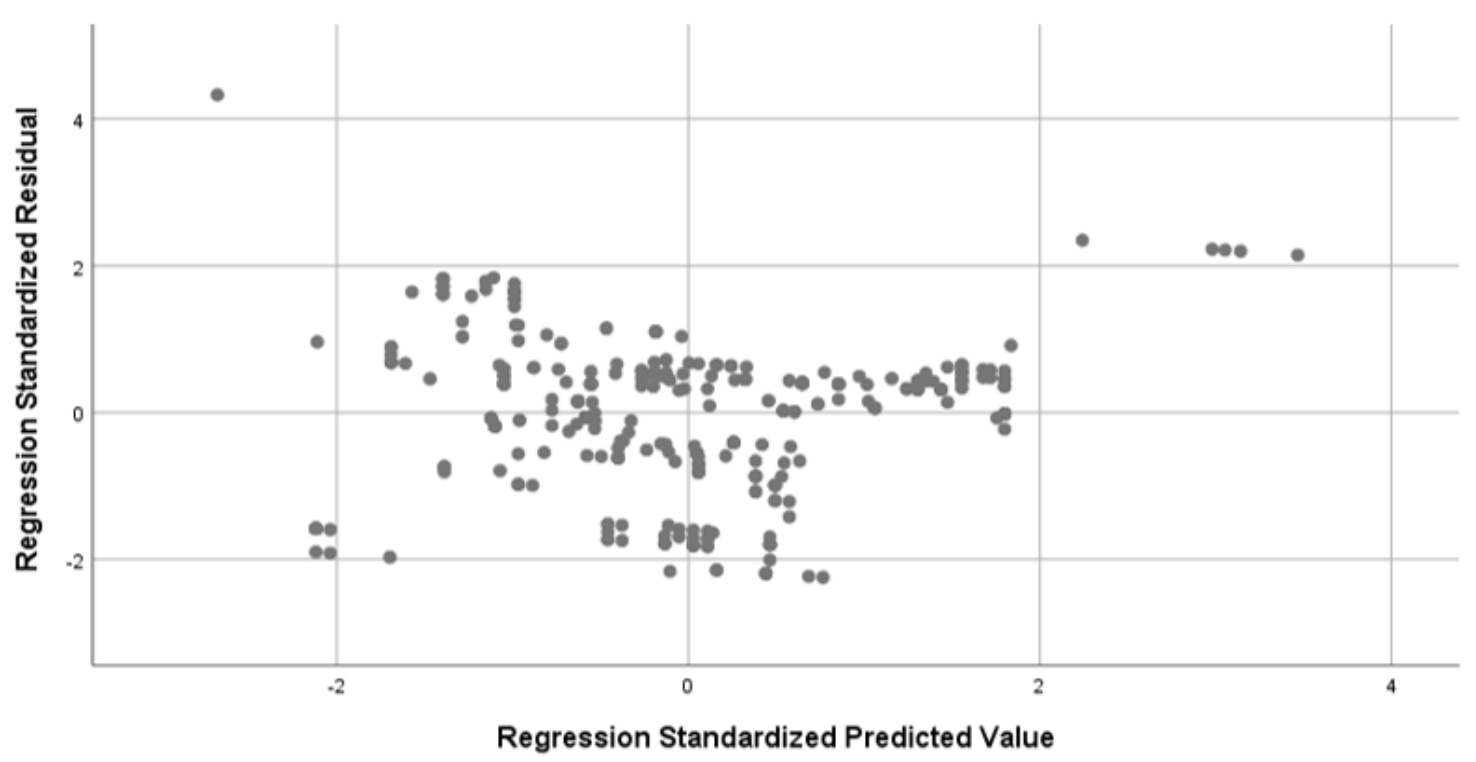

Figure 1. Scatterplot testing for homoscedasticity (Source: Primary Data, 2021)

\section{PRESENTATION OF DATA AND FINDINGS}

To test the hypotheses of this study, Pearson's correlation analysis and multiple linear regression coefficient analysis were carried out.

Before running the Pearson's correlation and multiple regression analysis, the researcher ensured that all assumptions were met. The first assumption is that the variables been studied should be measured at the interval or ratio level, implying that they should be continuous. Although this study made use of Likert scale, the scales were treated as continuous because each category had a defined value. The second assumption was that there should be a linear relationship and be normally distributed, which the analysis showed. The third assumption was that there should not be any outliers. To ensure that the data did not have any outlier, Grubb's test was carried out to check that there were no outliers.

The result of the test showed that there were no significant outliers. Furthermore, independence of observations was also ensured by running a Durbin-Watson test which showed a result of $d=2.1$ which indicates that autocorrelation is not present.

Another assumption that needs to be met before a multiple linear regression can be run is that the data needs to show homoscedasticity which is when the error variances are the same for all combinations of independent and moderator variables. To check for this, a test of scatterplot was conducted to show the regression standardized residual for the dependent and independent variables.

The scatterplot in Figure 1 shows the standardized values the model for the data will predict, against the standardized residuals obtained. As the predicted values increase (on the $x$-axis), the variation should be similar. The scatterplot above shows that this assumption has not been violated.

The final assumption tested was that the data must not show multi-collinearity. To test for multi-collinearity, the researchers ran the regression test in SPSS and then checked the VIF value. If the VIF value is between 1 and 10, then it can be deduced that there is no multi-collinearity. The result of the test run, showed a VIF of 1.056, meaning that there is no multi-collinearity. Therefore, this assumption was also met.

Once all the assumptions were met, the analysis was carried out. The results of the analysis, based on the hypotheses of this study, are presented. 
Table 2. Correlation matrix $(n=654)$

\begin{tabular}{lll}
\hline & SE & PRCA \\
\hline PRCA & $.109^{* *}$ & \\
SMA & $-.177^{* *}$ & $.294^{* *}$ \\
\hline
\end{tabular}

$* * p<.01 ;$ SE: Self-esteem; SMA: Facebook addiction; PRCA: Communication Apprehension

Table 3. Model summary

\begin{tabular}{lcccc}
\hline $\mathrm{R}$ & $\mathrm{R}$ square & Adjusted R square & $\mathrm{F}$ & $\mathrm{P}$ \\
\hline .362 & .131 & .128 & 48.94 & .0000 \\
\hline
\end{tabular}

a. Predictors: (Constant), self-esteem, communication apprehension

Table 4. Multiple linear regression coefficient

\begin{tabular}{lcccc}
\hline \multirow{2}{*}{ Independent variables } & \multicolumn{2}{l}{ Dependent variable } & & \\
\cline { 2 - 5 } & $\mathrm{B}(\mathrm{SE})$ & $\beta$ & $\mathrm{T}$ & $\mathrm{p}$ \\
\hline (Constant) & $3.240(.220)$ & & 14.736 & .000 \\
Self-esteem & $-.055(.010)$ & -.211 & -5.752 & .000 \\
Communication apprehension & $.100(.012)$ & .317 & 8.630 & .000 \\
\hline
\end{tabular}

Table 2 shows the correlation matrix among all the variables. The result of the correlations shows that selfesteem has a negative significant relationship with Facebook addiction $[r(654)=-.177, p<.001]$, implying that the lower their self-esteem, the more addicted these individuals are to social media.

The results also show a positive significant relationship between communication apprehension and Facebook addiction $[r(654)=.109, p<.001]$. This implies that individuals with high levels of communication apprehension are also more likely to be addicted to social media than those with lower levels of communication apprehension.

Table 3 presents the model summary of the regression. The result reveals that self-esteem and communication apprehension significantly predicted Facebook addiction $[F(2,651)=48.94, p<.0001]$. Both the predictor variables accounted for $13.1 \%$ of the variability in Facebook addiction.

Table 4 shows the coefficients and the unique contribution of all the predictor variables on the dependent variable. There was a negative significant relationship $(t=-5.752, \beta=-.211, p<.001)$ between self-esteem and Facebook addiction. This would mean that people with low self-esteem tend to spend more time on social media. In other words, those with low self-esteem are significantly more likely to be addicted to social media than those with high self-esteem.

Communication apprehension had a significant positive relationship $(t=8.630, \beta=.317, p<.001)$ with Facebook addiction, suggesting that individuals with higher social media use are more likely to have high communication apprehension and vice versa.

\section{DISCUSSION}

H1: There is a difference in the frequency of social media usage among those who have high levels of communication apprehension and those with low levels or no communication apprehension.

The results in Table 2 show a positive significant relationship between communication apprehension and Facebook addiction, implying that individuals with high levels of communication apprehension are also more likely to be addicted to social media than those with lower levels of communication apprehension. Therefore, it can be concluded that $\mathbf{H} \mathbf{1}$ is accepted.

The findings support those of Armstrong and Rubin (1989) who found out that people who have some level of communication apprehension generally prefer to make use of a medium instead of communicating faceto-face. Although Armstrong and Rubin's (1989) study was carried out long before social media and therefore 
was not in fact studying communication apprehension and Facebook addiction, the study did show that people with a higher level of communication apprehension generally prefer to make use of mediated communication, which social media is a form of. It can therefore be surmised that people with high levels of communication apprehension will prefer to communicate through a medium that allows them to communicate from a distance without having to physically be present. The findings of this study support a more recent study by McCord et al. (2014) that looks at the relationship between social anxiety and social media apprehension. The findings of their study showed that people with high levels of social anxiety tend to make use of social media frequently.

Similarly, the findings of this study also support previous research by Ellison et al. (2007), Mugaddas et al. (2017), and Nyagah et al. (2015) who all posit that social media provides an escape for people and helps boost their confidence levels, since it provides a platform for shy and introverted individuals to develop some social capital or improve on their social interactions as the restrictions involved in face-to-face communication are absent.

H2: There is a significant relationship between self-esteem and Facebook addiction.

H3: Those with low self-esteem are significantly more likely to be addicted to social media than those with high self-esteem.

Table 4 also shows a significant relationship between self-esteem and Facebook addiction. The implication is that people with low self-esteem tend to be more addicted to Facebook than those with high levels of selfesteem. Based on the foregoing, it can be concluded that $\mathbf{H} \mathbf{2}$ is also accepted.

Also, the findings showed that people with low self-esteem tend to spend more time on social media. In other words, those with low self-esteem are significantly more likely to be addicted to social media than those with high self-esteem. Based on the foregoing, it can also be deduced that $\mathbf{H} \mathbf{3}$ is accepted.

The findings of this study support those of Hawi and Samaha (2016), Kose and Dogan (2019), and Purnama et al. (2021) who all concluded that there is a negative relationship between social media usage and selfesteem. Their studies explained that Facebook addiction can be predicated by low-self-esteem and at the same time, low self-esteem can also lead to Facebook addiction. Pantic (2014) in a similar submission showed that social media usage can lead to depression, psychotic behavior and low self-esteem. It is worth noting, that these negative effects were not observed in the study nor self-reported among the participants of the study. This however leaves room for more studies on this phenomenon especially considering the recent efforts by social media companies to reduce hate speech, online bullying, and other efforts to ensure that the platform is as welcoming to all as possible. The current study however showed a relationship between both variables but did not explore the nature of this relationship.

H4: Social communication apprehension and self-esteem is a predictor to Facebook addiction.

Finally, the findings of this study showed that self-esteem and communication apprehension significantly predicted Facebook addiction. It is concluded in this study that people with low levels of self-esteem and high levels of communication apprehension are significantly more likely to become addicted to social media than people with just one of these traits. To clarify, someone that has both traits (low self-esteem and high communication apprehension) are more likely to become addicted to social media than someone with a moderate to high self-esteem and high level of communication apprehension. Therefore, $\mathbf{H} \mathbf{4}$ is accepted.

The findings of this study support the "the poor gets richer' hypothesis or the compensation effect, which suggests that people who are socially inept or awkward are more likely to spend a lot of time online, trying to compensate for their offline failings. By extension, "the rich gets richer" or the social enhancement effect is also supported by the findings of this study. The evidence, as reflected in the findings of this study, shows that people that already do very well in terms of face-to-face social interactions also tend to do well in online environments, while individuals that are not particularly adept at offline socializations tend to become addicted to the online environment as a way to compensate, thereby lending credence to "the rich gets richer and the poor gets richer hypothesis". 


\section{LIMITATIONS OF THE STUDY}

The limitations of this study presented itself in two ways, methodological limitations, and limitations in terms of previous studies seeking to identify the relationship between social communication apprehension, selfesteem and Facebook usage.

In terms of methodological limitations, the study could have benefitted from examining other social media platforms like YouTube and Twitter since they are also significantly popular among Ugandans. However, Facebook was selected because user data was readily available and easily accessible. Furthermore, the study population was limited to just university students, excluding a large portion of the youth population that also access and make use of social media in Uganda. This decision was as a result of the pandemic which seriously restricted movement since 2020 and therefore made interactions outside campuses much more difficult. Also, this study sought to find out the relationship between self-esteem and Facebook usage but failed to explore the nature of this relationship.

Also, very little had been done on the subject area, especially when considering the interactions and relationships between the three different variables considered in this study. While the issue of communication apprehension and social media usage has been well discussed in scholarship, very little has been done on the relationship between self-esteem, social media usage and communication apprehension. This study is arguable one of the first to address this phenomenon from this perspective.

\section{CONCLUSIONS AND RECOMMENDATIONS}

This study has expanded research into the relationship between social communication apprehension and Facebook addiction. At a time when social media has completely changed the world all around us and has made it become a truly 'global village', it is important to understand how different people fit into this new social media landscape and how character traits or flaws affect how social media is used. In the case of this study, two different character traits were considered: social communication apprehension and self-esteem. The findings showed that both these traits serve as significant predictors of the frequency of social media usage or Facebook addiction. It is however worth noting that this study limited itself to university students and individuals of university school age, therefore a different study focusing on high school students, since they are at their most impressionable age, can be carried out. Similarly, a study that looks at the long-term effect of social media usage and its capability to change behavior (for instance make an introvert less introverted by boosting their self-confidence) will also help shed light on the effect of social media usage on behavior.

This study sought to find out if there is a difference in the frequency of social media usage among those who have a high level of communication apprehension and those with no communication apprehension. The findings showed that indeed there is a difference and that those with a higher level of communication apprehension have a higher tendency or likelihood to be addicted to social media usage. The reason for this can be attributed to the fact that such individuals want to compensate for their lack of social capital in the offline world.

In a similar vein, it was determined that individuals with low self-esteem are significantly more likely to frequently make use of social media than those with a higher level of self-esteem. Low self-esteem usually manifests through different behavioral traits, such as, social awkwardness, quietness, or even bullying. To make up for their 'shortcomings', those individuals may turn to social media to better express themselves. Future studies can take a further look at this phenomenon.

Finally, before embarking on this study, it was observed that there is a dearth of literature on the phenomenon studied, despite the fact that Africa is one of the fastest adopters of social media with Nigeria alone having more than 50 million social media users. So, it is a surprise that very little research has been carried out that looks at the social media and communication apprehension in Africa. By embarking on this study, the researchers have expanded the discourse on social communication apprehension and social media usage, to include an African perspective. 
Author contributions: All authors were involved in concept, design, collection of data, interpretation, writing, and critically revising the article. All authors approve final version of the article.

Funding: The authors received no financial support for the research and/or authorship of this article.

Declaration of interest: Authors declare no competing interest.

Data availability: Data generated or analysed during this study are available from the authors on request.

\section{REFERENCES}

Agrawal, S., \& Krishna, S. M. (2021). Communication apprehension and psychological well-being of students in online learning. Behavioral Sciences, 11(11), 145. https://doi.org/10.3390/bs11110145

Andreassen, C. S., Torsheim, T., Brunborg, G. S., \& Pallesen, S. (2012). Development of a Facebook addiction scale. Psychological Reports, 110(2), 501-517. https://doi.org/10.2466/02.09.18.PR0.110.2.501-517

Armstrong, C. B., \& Rubin, A. M. (1989). Talk radio as interpersonal communication. Journal of Communication,39(2), 84-94. https://doi.org/10.1111/j.1460-2466.1989.tb01031.x

Awobamise, A. O., Jarrar, Y., \& Nnauuife, S. (2019). Social media, sexual harassment and rape discourse in Nigeria: An exploratory study. Journal of Social Sciences and Humanities, 4(19), 1035-1045.

Boyd, D. M., \& Ellison, N. B. (2007). Social network sites: Definition, history, and scholarship. Journal of Computer-Mediated Communication, 13(1), Article 11. https://doi.org/10.1111/j.1083-6101.2007. 00393.x

Chou, H.-T. G., \& Edge, N. (2012). "They are happier and having better lives than I am": The impact of using Facebook on perceptions of others' lives. Cyberpsychology, Behavior, and Social Networking, 15, 117121. https://doi.org/10.1089/cyber.2011.0324

Creswell, J. (2003). Research design: Qualitative, quantitative and mixed methods approaches. SAGE.

da Veiga, G. F., Sotero, L., Pontes, H. M., Cunha, D., Portugal, A., \& Relves, A. P. (2019). Emerging adults and Facebook use: The validation of the Bergen Facebook addiction scale (BFAS). International Journal of Mental Health and Addiction, 17, 279-294. https://doi.org/10.1007/s11469-018-0018-2

Ellison, N., Steinfield, C., \& Lampe, C. (2007). The benefits of Facebook "friends:" Social capital and college students' use of online social network sites. Journal of Computer-Mediated Communication, 12, 11431168. https://doi.org/10.1111/j.1083-6101.2007.00367.x

Erdogan, Y. (2008). Exploring the relationships among Internet usage, Internet attitudes and loneliness of Turkish adolescents. Cyberpsychology: Journal of Psychosocial Research on Cyberspace,2(2), Article 4.

Feinstein, B. A., Hershenberg, R., Bhatia, V., Latack, J. A., Meuwly, N., \& Davila, J. (2013). Negative social comparison on Facebook and depressive symptoms: Rumination as a mechanism. Psychology of Popular Media Culture, 2, 161-170. https://doi.org/10.1037/a0033111

Gadekar, R., \& Ang, P. H. (2020). Is social media use socially enhancing or compensating? Journal of Creative Communications, 15(3), 269-288. https://doi.org/10.1177/0973258620943705

Griffiths, M. D. (2005). A "components" model of addiction within a biopsychosocial framework. Journal of Substance Use, 10(4), 191-197. https://doi.org/10.1080/14659890500114359

Hawi, N., \& Samaha, M. (2016). The relations among Facebook addiction, self-esteem, and life satisfaction in university students. Social Science Computer Review, 35(5), 576-586. https://doi.org/10.1177/ 0894439316660340

Heatherton, T. F., \& Polivy, J. (1991). Development and validation of a scale for measuring state self-esteem. Journal of Personality and Social Psychology, 60, 895-910. https://doi.org/10.1037/0022-3514.60.6. 895 
ISS. (2021). Uganda social media battleground is not just an African trend. https://issafrica.org/isstoday/ugandas-social-media-battleground-is-not-just-an-african-trend

Kaplan, A. M., \& Haenlein, M. (2010). Users of the world, unite! The challenges and opportunities of social media. Business Horizons, 53, 59-68. https://doi.org/10.1016/j.bushor.2009.09.003

Kose, O. B., \& Dogan, A. (2019). The relationship between Facebook addiction and self-esteem among Turkish University students. Addicta: The Turkish Journal on Addictions, 16(1), 175-190. https://doi.org/ 10.15805/addicta.2019.6.1.0036

Kross, E., Verduyn, P., Demiralp, E., Park, J., Seungjae Lee, D., Lin, N, Shablack, H., Jonides, J., \& Ybarra, O. (2013). Facebook use predicts declines in subjective well-being in young adults. PLoS One, 8, e69841. https://doi.org/10.1371/journal.pone.0069841

Loureiro, M., Loureiro, N., \& Silva, R. (2020). Differences of gender in oral and written communication apprehension of university students. Education Sciences, 10, 379. https://doi.org/10.3390/ educsci10120379

McCord, B., Rodebaugh, T. L., \& Levinson, C. A. (2014). Facebook: Social uses and anxiety. Computers in Human Behavior, 34, 23-27. https://doi.org/10.1016/j.chb.2014.01.020

McCroskey, J. C. (2009). Communication apprehension: What have we learned in the last four decades? Human Communication, 12(2), 157-171.

McCroskey, J. C., \& Sheahan, M. E. (1978). Communication apprehension, social preference, and social behavior in a college environment. Communication Quarterly, 26(2), 41-45. https://doi.org/10.1080/ 01463377809369292

McCroskey, J. C., Beatty, M. J., Kearney, P., \& Plax, T. G. (1985). The content validity of the PRCA-24 as a measure of communication apprehension across communication contexts. Communication Quarterly, 33(3), 165-173. https://doi.org/10.1080/01463378509369595

Miyata, K., \& Kobayashi, T. (2008). Causal relationship between Internet use and social capital in Japan. Asian Journal of Social Psychology, 11, 42-52. https://doi.org/10.1111/j.1467-839X.2007.00242.x

Muqaddas, J., Sanobia, A. S., \& Nawaz, A. (2017). Impact of social media on self-esteem. European Scientific Journal, 13(23), 329-341. https://doi.org/10.19044/esj.2017.v13n23p329

Pantic, I. (2014). Online social networking and mental health. Cyberpsychology, Behavior, and Social Networking, 17(10), 652-657. https://doi.org/10.1089/cyber.2014.0070

Pitt, L. F., \& Ramaseshan, B. (1990). Apprehension about communication and salespersons' performance. Psychological Reports, 67, 1355-1362. https://doi.org/10.2466/pr0.1990.67.3f.1355

Punyanunt-Carter, N. M., Cruz, J. J., \& Wrench, J. S. (2018). Analyzing college students' social media communication apprehension. Cyberpsychology, Behavior and Social Networking, 21(8), 511-515. https://doi.org/10.1089/cyber.2018.0098

Purnama, H. Darmawati, I., \& Mulyatin, W. (2021). Facebook addiction and the association with self-esteem among adolescents in rural areas of Indonesia. In The 4th International Virtual Conference on Nursing, KnE Life Sciences (pp. 671-679). https://doi.org/10.18502/kls.v6i1.8741

Richmond, V. P., \& McCroskey, J. C. (1995). Communication: Apprehension, avoidance, and effectiveness. Gorsuch Scarisbrick.

Rohani, V. A., \& Hock, O. S. (2010). On social network web sites: Definition, features, architectures and analysis tools. Journal of Advances in Computer Research, 2, 41-53. 
Schachter, S. (1959). The psychology of affiliation: Experimental studies of the sources of gregariousness. Stanford University Press.

Scott, C. R., \& Rockwell, S. C. (1997). The effect of communication, writing, and technology apprehension on likelihood to use new communication technologies. Communication Education, 46, 44-62. https://doi.org/10.1080/03634529709379072

Sealy, M. K. (2021). Communication in the time of COVID-19: An examination of imagined interactions and communication apprehension during the COVID-19 pandemic. Imagination, Cognition, and Personality, 41, 158-186. https://doi.org/10.1177/02762366211021076

Sheldon, P. (2008). The relationship between unwillingness-to-communicate and students' Facebook use. Journal of Media Psychology, 20(2), 67-75. https://doi.org/10.1027/1864-1105.20.2.67

Statista. (2021). Number of monthly active Facebook users worldwide. https://www.statista.com/statistics/ 264810/number-of-monthly-active-facebook-users-worldwide/

Tazghini, S., \& Siedlecki, K. (2013). A mixed approach to examining Facebook use and its relationship to selfesteem. Computers in Human Behavior, 29, 827-832. https://doi.org/10.1016/j.chb.2012.11.010

Tufekci, Z. (2010). Who acquires friends through social media and why? "Rich get richer" versus "seek and ye shall find". In Proceedings of the Fourth International AAAI Conference on Weblogs and Social Media (pp. 170-177).

Valkenburg, P. M. (2017). Understanding self-effects in social media. Human Communication Research, 43(4), 477-490. https://doi.org/10.1111/hcre.12113

Valkenburg, P. M., Peter, J., \& Schouten, M. A. (2006). Friend networking sites and their relationship to adolescents' well-being and social self-esteem. Cyberpsychology, Behavior, and Social Networking, 9, 584-590. https://doi.org/10.1089/cpb.2006.9.584

Wang, Q., Fink, E. L., \& Cai, D. A. (2008). Loneliness, gender, and parasocial interaction: A uses and gratifications approach. Communication Quarterly, 56(1), 87-109. https://doi.org/10.1080/ 01463370701839057

Wang, Z., Tchernev, J. M., \& Solloway, T. (2012). A dynamic longitudinal examination of social media use, needs, and gratifications among college students. Computers in Human Behavior, 28, 1829-1839. https://doi.org/10.1016/j.chb.2012.05.001

Watson, B. R. (2007). Speaking up in the 21st century: The effects of communication apprehension and Internet self-efficacy on use of social networking websites [Unpublished master thesis]. University of Missouri.

Wrench, J. S., Brogan, S. M., McCroskey, J. C., \& Jowi, D. (2008). Social communication apprehension: The intersection of communication apprehension and social phobia. Human Communication: Pacific and Asian Communication Association, 11(4), 409-430.

Zywica, J., \& Danowski, J. (2008). The faces of Facebookers: Investigating social enhancement and social compensation hypotheses; predicting Facebook ${ }^{\mathrm{TM}}$ and offline popularity from sociability and selfesteem, and mapping the meanings of popularity with semantic networks. Journal of ComputerMediated Communication, 14, 1-34. https://doi.org/10.1111/j.1083-6101.2008.01429.x

Correspondence: Yosra Jarrar, American University in Dubai, United Arab Emirates. E-mail: yjarrar@aud.edu 